in the stomach. After this he steadily improved and soon declared that his stomach felt much better than before the operation. His temperature never rose above $99^{\circ} \mathrm{F} . \mathrm{He}$ naturally lost weight for a time after the operation but as soon as he was allowed food he was always hungry. By June 13th his weight had risen to 122 pounds and when be left the infirmary on June 17th he felt better than he had done for years. Four months later he weighed 152 pounds, and though he said that the scar in the abdowinal wall felt weak when he had to lift three-quarters of a hundredweight he maintained that his stomach was " all right inside."

Remarks by Mr. MoTHERsole.-There can be little doubt that in Case 1 there was a perforation of the stomach in December, 1900. This was probably small and became occluded with lymph which glued the stomach to the anterior surface of the spleen. Ulceration went on and eroded the spleen substance, and it appears certain that the frequent and severe hæmorrhages from which the patient suffered came from the splenic vessels. It does not seem that much could have been done for the patient by operation in August, 1903. The only operation that could have relieved her then would have been excision of the spleen with closure of the gastric opening. And in her condition at that time she could not have stood such a severe operation. In the light of after events it seems unfortunate that a more vigorous search was not made for the perforation in 1900 , even to the extent of breaking down the limiting adhesions. This case shows the risks which adhesion of a gastric ulcer to another organ involves. It would seem adrisable in most cases when a perforated gastric ulcer appears to have been occluded without operation to search for, and to excise, it in order to prevent subsequent trouble. Adhesion to a solid organ is likely to hinder healing of the ulcer by preventing contraction of the base.

In Case 3 we were fortunate in having the patient in hospital at the time of perforation and though the operation was not performed so soon as it should have been the patient did not have to suffer the pains and other drawbacks of a journey. The operation had the effect of a pyloroplasty and seemed entirely to relieve the gastric retention from which he suffered. It seems a matter for congratulation that a gastro-jejunostomy was not done when first proposed. If perforation had occurred shortly after the symptoms might have been attributed to the operation.

Recoveries after operation for perforating gastric ulcer have of late sears been comparatively common and one almost feels it necessary to apologise for publishing sucl cases. Yet it is worth while to remember that ten sears ago such recovery was almost unknown. Mr. A. W. Maro Robson's first successful operation for this condition was in 1897. About 16 years ago two patients suffesing from peritonitis were admitted to the wards of one of the largest London hospitals. Each was operated on by a distinguished surgeon but in neither case was the existence of a perforation of the stomach discovered until the post-mortem examination. Since then abdominal surgery has made immense progress. I must own to having had three un. successful operations for perforating gastric ulcer before I met with a success : one of these was very disappointing and lived for nearly a fortnight after the operation, dying from gastric hæmorrhage and hypophrenic abscess. It is satis factory to be able to say that the last three operalions which I have seen for this condition at the Bolton Infirmary have all been successful. ${ }^{1}$

I am glad to find that Robson and Moynihan in the ir book on "Diseases of the Stomach" speak so decidedly on the point of "absence of liver dulness" in perforating gastric ulcer. "Its presence or absence is void of any significance, and is unreliable as an aid to diagnosis." Personally, I have never attached any importance to the absence of this sign and in at least six cases have not fourd sufficient free gas in the peritoneum to give rise to it. It is conceivable that absence of liver dulness may be due to any one of three conditions: (1) distension of the intestines with gas, causing them to overlap the liver: (2) the presence of a certain amount of fluid in the peritoneum allowing the bowel to float up over the liver; and (3) free gas in the peritoneum. In the first of Mr. H. S. Clngg' interesting series of perforated duodenal ulcers ${ }^{2}$ he states

1 Since writing the above we have had two more successful operation for perforating gastric ulcer at the Bolton Infimary, mak:ng five consecutire recoveries. One of these was in a patient on whom $I$ had dor. a gastro-jejunostomy two and a half years before. that the clinical phenomena pointed to the presence of free gas and fluid in the peritoneum, but on opening the abdomen he only says that fluid escaped. If no free gas was found at the operation the signs which were considered to indicate its presence were probably due to the prestnce of fluid with some distension of the bowels.

\section{ROYAL BUCKINGHAMSHIRE HOSPITAL, AYLESBURY.}

A CASE OF SURGICAL EMPHYSEMA RESULTING FROM A FALL. (Under the care of Mr. HoracE RosE.)

For the notes of the case we are indebted to Mr. Russell F. Palmer, house surgeon.

The patitnt, a boy, aged six years, was taken to the hospital with a history of a sudden fall over a step ten or 15 mirutes previously. On admission his neck was very much swollen, the swelling extending up both sides of the face, and involving the lower right eselid which could scarcely be opened. His respirations were 30 , the pulse was 100 , and the colour was good (although he was said to bave been slightly "blue"). "There was no wound involving the skin anywhere, the nose was uninjured, and the re was no air in the pleural cavities. The swelling was solt, doughy, and gare the characteristic crepitus of air in the subcutaneous tissues. He complained at the time of the accident of pain over the trachea but afterwards of nore in any particular region although he was terder over all the swelling. His voice was a little lusky and he coughed but little, bringing up neitter mucus nor blood. Tre empbysema extended rapidly and suread to the other eyelids, the whole of the chest wall, and part of the abdomen. The child was kept in bed, no special treatment being adopted. On the evening of the second day be developed a tenoperature of $104^{\circ} \mathrm{F}$. kut ky the following norning it was normal again. The air was rapidly absorber and the patient left hospital quite well at the $t$ nd of a week.

Remarks by Mr. PALMER.-The explanation of the emphysema seems to be that in falling the head was thrown suddenly and violently back, rupturirg part of one of the intert racheal muscles with the underly ing mucous membrane, thus allowing the escape of air from the trachea.

\section{Aitrotical Societics.}

Edinburgh Obstetrical Society.-A meeting of this society was held on July 12th, Professor A. R. Simpson, Vice-President, being in the chair.-Dr. F. W. N. Haultain read a pi per on a series of cases of "Axial Rotation" in its Relation to the Pelvic Generative Organs. He said that the abdominal pelvic organs from their moveable character were liable to rotation of their attachments. Out of 16 cases met with in pelvic abdominal surgery two were a-sociated with uterine growths and in 14 the ovary was implicated. The 16 costs were composed of 12 simple ovarian tumours, one ovarian cyst with pregnarcy, one normal ovary, one subserous pedunculated fibromjoma, and one rotation of the entire uterus with interstitia fibroid growth. Twists of the pedicle might for clinical purposes be considered as acute permanent, acute ter porary, or chronic permanent. Rotation of the pedicle must interfere with the normal circulation of the affected organ, particularly obstructing the venous return, giving rise to all the conditions as sociated with renous congestion In one case intense sfmutoms arose from a two-thirds axial uterine rotation, jet ro acute sjmptoms arose in anotler case with a nariow pedicle twisted four times. The symptoms associated with twisting of the pedicle and acute -trangulation were intense pain in the abdomen, shock, fever, and rapid pulse; these were the same symptcms as those of acute strangulation of the gut without stercoraceous romiting. Chronic or slow twists might have nore of these symptoms and only became appirent duing the progress of an operation. Pain, thongh frequenily met with, might be entirely absent, even with strorg adhesior s to the sur rounding structures. Dr. Haultain gave details of a case where acute s\} mptoms with a temperature of $101 \cdot 5^{\circ} \mathrm{F}$. were produced by a congested hard fibromyomatous tumour 